\title{
Pulmonary changes on HRCT scans in nonsmoking females with COPD due to wood smoke exposure*
}

\author{
Alterações tomográficas pulmonares em mulheres não fumantes com \\ DPOC por exposição à fumaça da combustão de lenha \\ Maria Auxiliadora Carmo Moreira, Maria Alves Barbosa, \\ Maria Conceição de Castro Antonelli Monteiro de Queiroz, \\ Kim Ir Sen Santos Teixeira, Pedro Paulo Teixeira e Silva Torres, \\ Pedro José de Santana Júnior, Marcelo Eustáquio Montadon Júnior, \\ José Roberto Jardim
}

\begin{abstract}
Objective: To identify and characterize alterations seen on HRCT scans in nonsmoking females with COPD due to wood smoke exposure. Methods: We evaluated 42 nonsmoking females diagnosed with wood smokerelated COPD and 31 nonsmoking controls with no history of wood smoke exposure or pulmonary disease. The participants completed a questionnaire regarding demographic data, symptoms, and environmental exposure. All of the participants underwent spirometry and HRCT of the chest. The COPD and control groups were adjusted for age (23 patients each). Results: Most of the patients in the study group were diagnosed with mild to moderate COPD (83.3\%). The most common findings on HRCT scans in the COPD group were bronchial wall thickening, bronchiectasis, mosaic perfusion pattern, parenchymal bands, tree-in-bud pattern, and laminar atelectasis ( $p<0.001$ vs. the control group for all). The alterations were generally mild and not extensive. There was a positive association between bronchial wall thickening and hour-years of wood smoke exposure. Centrilobular emphysema was uncommon, and its occurrence did not differ between the groups $(p=0.232)$. Conclusions: Wood smoke exposure causes predominantly bronchial changes, which can be detected by HRCT, even in patients with mild COPD.
\end{abstract}

Keywords: Biomass; Smoke; Tomography, X-ray computed; Pulmonary disease, chronic obstructive.

\section{Resumo}

Objetivo: ldentificar e caracterizar alterações na TCAR de tórax em mulheres com DPOC causada por exposição à fumaça da combustão de lenha. Métodos: Foram selecionadas 42 pacientes com DPOC relacionada à exposição à fumaça de lenha, não fumantes, e 31 mulheres não fumantes e sem história de exposição à fumaça de lenha ou de doença pulmonar. Empregou-se um questionário para a obtenção de dados demográficos e informações sobre sintomas e exposições ambientais. Todas as participantes realizaram espirometria e TCAR de tórax. Os grupos DPOC e controle foram ajustados por idade, com 23 pacientes cada. Resultados: A maioria das pacientes do grupo de estudo apresentava DPOC de leve a moderado (83,3\%). Os achados de TCAR mais frequentes no grupo DPOC foram espessamento das paredes brônquicas, bronquiectasias, perfusão em mosaico, bandas parenquimatosas, padrão de árvore em brotamento e atelectasias laminares ( $p<0,001$ para todos na comparação com o grupo controle). As alterações, em geral, foram leves e de pequena extensão. Houve uma associação positiva entre espessamento das paredes brônquicas e duração da exposição à fumaça de lenha em horas-ano. 0 achado de enfisema centrolobular foi infrequente e não diferiu entre os grupos $(p=0,232)$. Conclusões: A exposição à fumaça de lenha provoca alterações predominantemente brônquicas, que podem ser detectadas por TCAR, mesmo nos casos de DPOC leve.

Descritores: Biomassa; Fumaça; Tomografia computadorizada por raios X; Doença pulmonar obstrutiva crônica.

\footnotetext{
* Study carried out at the Federal University of Goiás School of Medicine Hospital das Clínicas, Goiânia, Brazil. Correspondence to: Maria Auxiliadora Carmo Moreira. Hospital das Clínicas da Universidade Federal de Goiás, Faculdade de Medicina. Primeira Avenida s/n, Serviço de Pneumologia, $2^{\circ}$ andar, Setor Universitário, CEP 74605-020, Goiânia, G0, Brasil. Tel. 5562 269-8385. E-mail: helpuol@uol.com.br

Financial support: This study received partial financial support from the Fundação de Amparo à Pesquisa do Estado de Goiás (FAPEG, Goiás Research Foundation).

Submitted: 4 November 2012. Accepted, after review: 14 February 2013.
} 


\section{Introduction}

In developing countries, biomass is still widely used as a source of energy for cooking and indoor heating. It is estimated that half of the world population uses biomass, which consists of unprocessed wood (firewood) or processed wood (charcoal), dung, and crop residues. ${ }^{(1)}$

Numerous studies have shown that, among females exposed to biomass smoke, the prevalence of COPD is high and the risk of developing the disease is significantly increased. ${ }^{(2)}$ It is estimated that 25-45\% of all COPD patients have never smoked. ${ }^{(3)}$ It is also known that the number of people who are exposed to smoke from biomass combustion is significantly higher than is that of those who are exposed to tobacco smoke (approximately 3 billion vs. 1.01 billion). ${ }^{(3)}$

There is a growing interest in learning more about the structural changes resulting from the inhalation of biomass smoke in order to gain a deeper understanding of the pathophysiology of biomass smoke-related obstructive lung disease. ${ }^{(4)}$ We searched the literature for studies employing HRCT in order to evaluate pulmonary changes caused by biomass smoke exposure and found only ten studies..$^{(5-14)}$ However, nine of those studies are related to the use of a combination of types of biomass (dung, crop residues, and firewood), and only one of those studies examined exposure to wood smoke alone (in 12 women). ${ }^{(9)}$ This heterogeneity of sources of smoke exposure makes it difficult to compare the individuals studied. The abovementioned study showed that bronchial lesions are more common in individuals who inhale wood smoke, whereas alveolar lesions are more common in cigarette smokers. ${ }^{(9)}$ However, to our knowledge, there have been no CT studies of lung lesions in COPD patients exposed to wood smoke, the findings in such patients being compared with those in a control group of nonsmoking females with no history of exposure to biomass smoke.

The objective of the present study was to identify and characterize alterations seen on HRCT scans in nonsmoking females with COPD due to prolonged exposure to wood smoke from cooking.

\section{Methods}

The present study was conducted in central Brazil between 2008 and 2011. The inclusion criteria for COPD patients were as follows: being $\geq 40$ years of age; having been exposed to wood smoke $\geq 80$ hour-years for at least 10 years; not being a smoker; and having received a clinical and spirometric diagnosis of COPD. The inclusion criteria for controls were as follows: being $\geq 40$ years of age; living in an urban area; not being a smoker; having no history of wood smoke exposure; and having normal spirometry results. All of the females who participated in the present study gave written informed consent. The exclusion criteria for COPD patients and controls were as follows: presenting with clinical findings (of an evaluation performed by a pulmonologist in the present study or of a previous evaluation by a pulmonologist, as reported in the medical records) suggestive of a history of asthma, rhinitis, or any extrapulmonary disease that might affect lung function; and having a positive bronchodilator test, FEV increasing by $\geq 12 \%$ and $200 \mathrm{~mL}^{\left({ }^{(15)}\right.}$

We used a shorter version of a questionnaire that was previously used in a population-based study conducted in Brazil ${ }^{(16)}$ in order to collect demographic and clinical data: respiratory symptoms (cough, phlegm, wheezing, and dyspnea), duration (in years and daily hours) of exposure to wood smoke; duration (in years) of exposure to passive smoking by living in a household with smokers; and duration (in years) of residence in a rural area. The degree of dyspnea was quantified by the Medical Research Council (MRC) scale. ${ }^{(17)}$

The cumulative exposure to wood smoke was expressed in hour-years, calculated as the number of years cooking with a wood stove multiplied by the mean number of hours the participant reported to spend, daily, in this activity. The criterion of wood smoke exposure $\geq 80$ hour-years for at least 10 years was based on the levels of exposure considered significant in similar studies. ${ }^{(18)}$

The study participants underwent spirometry before and after the use of a bronchodilator (albuterol, $400 \mu \mathrm{g}$ ), FVC, FEV ${ }_{1}$, and the $\mathrm{FEV}_{1}$ I $\mathrm{FVC}$ ratio being measured. The diagnostic criteria for COPD were as follows: being $\geq 40$ years of age; having an $\mathrm{FEV}_{1} / \mathrm{FVC}$ ratio below the lower limit of normality and $<0.70^{(19,20)}$; having been exposed to smoke from wood stoves; and having 
a history of chronic dyspnea, chronic cough, or both, unrelated to other causes.

The severity of COPD was determined in accordance with the Global Initiative for Chronic Obstructive Lung Disease spirometric classification. ${ }^{(20)}$

The pulmonary function tests were performed in accordance with the Brazilian Thoracic Association guidelines. ${ }^{(21)}$ The predicted values used in the present study were those of Pereira et al. ${ }^{(22)}$

In our analysis of HRCT scans, we used the criteria established by the Brazilian Thoracic Association illustrated Brazilian consensus of terms and fundamental patterns in chest CT scans. ${ }^{(23)}$ In order to locate abnormalities, we used the following criteria: upper lung fields-from the apices to the carina; middle lung fieldsfrom the carina to the mitral valve; and lower lung fields-from the mitral valve to the lung bases. The degree of pulmonary impairment was determined on the basis of the number of lung lobes showing the following changes: parenchymal bands; mosaic perfusion pattern; atelectasis; tree-in-bud pattern; and traction bronchiectasis. The degree of bronchial wall thickening was classified as follows: grade 1-up to 20\% of the diameter of the adjacent pulmonary artery; grade 2-greater than 20\% and less than 50\% of the diameter of the adjacent pulmonary artery; and grade 3-50-100\% of the diameter of the adjacent pulmonary artery. Bronchiectasis was graded as follows: grade 1-the ratio between the internal diameter of the bronchus and the diameter of the adjacent artery was 0.7-1.0; grade 2 -the internal diameter of the bronchus was increased but was less than twice the diameter of the adjacent artery; and grade 3-the internal diameter of the bronchus was more than twice the diameter of the adjacent artery. Centrilobular emphysema was classified as follows ${ }^{(24,25)}$ : absent; areas of $<5 \mathrm{~mm}$; areas $>5 \mathrm{~mm}$; diffuse areas of low attenuation that were not interspersed with areas of normal lung; and large, confluent areas of low attenuation.

In order to take HRCT scans, we used either a Somatom Emotion ${ }^{\text {ni }} 6$ CT scanner (Siemens, Munich, Germany) or an Aquilion" 16 CT scanner (Toshiba, Tokyo, Japan). The images were acquired during a maximal inspiratory maneuver, as follows: collimation, $1 \mathrm{~mm} ; 125 \mathrm{kV}$; $160 \mathrm{~mA}$; and acquisition time, $0.75 \mathrm{~s}$. The intervals between images were of $10 \mathrm{~mm}$, with the patient in the supine position. The images were reconstructed with a high-resolution algorithm, with a $512 \times 512$ pixel matrix. Lung and mediastinal window images were available for analysis. No contrast agent was used.

The images were independently analyzed by three radiologists (one general radiologist with 35 years of experience and two thoracic radiologists, one with 2 years of experience and the other with 12 years of experience). In cases of discordance, the result was based on consensus. ${ }^{(25)}$ All images were evaluated in Digital lmaging and Communications in Medicine format. The radiologists had no information regarding the clinical diagnosis of the study participants or the existence of risk factors for COPD. They were aware of the fact that it was a study aimed at evaluating females exposed to wood smoke.

For the statistical analysis, we used the IBM SPSS Statistics software package, version 15.0 (IBM Corporation, Armonk, NY, USA). We used the Student's t-test in order to compare the groups in terms of quantitative variables with normal distribution and the Mann-Whitney $\mathrm{U}$ test in order to compare the groups in terms of variables with non-normal distribution. The chi-square test and Fisher's exact test were used in order to compare the frequencies of qualitative variables and calculate the risk that the independent variable represented. By logistic regression analysis, we analyzed the association between abnormal HRCT findings and other variables. We used Pearson's test in order to detect correlations among variables with normal distribution. In order to balance the sample, the females in the COPD group and those in the control group were matched for age. The oldest females in both groups were excluded, as were the youngest. The odds ratio was calculated with a confidence interval of 95\%, and values of $p<0.05$ were considered significant.

The present study was approved by the Research Ethics Committee of the Federal University of Goiás Hospital das Clínicas on April 4, 2008 and on September 21, 2010 (Amendment 1), under registration no. 018/08.

\section{Results}

In the present study, the COPD group comprised 42 females and the control group comprised 31. It was extremely difficult to recruit females from 
among those living in the region where the study was conducted, particularly elderly females who had never cooked with wood stoves.

The participants were sequentially recruited from among those being treated at either of two general clinical medicine outpatient clinics and from among those being treated at the gynecology outpatient clinic of a university hospital, as well as being recruited from among patients without a confirmed diagnosis of respiratory disease seeking the aforementioned university hospital for spirometry. The females in the control group were selected from among those studying at an open university for the elderly.

The mean age was higher in the COPD group than in the control group $(70.8 \pm 8.5$ years vs. $58.9 \pm 7.2$ years; $p<0.001)$, as was the mean duration (in years) of rural residence (40.7 \pm 17.7 years vs. $3.61 \pm 5.1$ years; $p=0.001$ ). All of the females in the COPD group resided in rural areas and worked predominantly as housecleaners or homemakers, sporadically working in the agricultural production of grains. There were no statistically significant differences between the COPD and control groups regarding the mean duration of passive exposure to tobacco smoke (20.6 \pm 18.0 years vs. $29.2 \pm 21.0$ years; $\mathrm{p}=0.70$; Table 1).

Most of the patients with COPD had one or more of the following respiratory symptoms: cough;

Table 1 - Demographic characteristics, clinical characteristics, and data regarding wood smoke exposure in 42 patients with COPD. ${ }^{\text {a }}$

\begin{tabular}{|c|c|}
\hline Variable & Result \\
\hline Age, years & $70.8 \pm 8.5$ \\
\hline Rural residence, years & $40.7 \pm 17.7$ \\
\hline Passive smoking, years & $29.2 \pm 21.0$ \\
\hline Wood smoke exposure, h/day & $6.0 \pm 1.9$ \\
\hline Wood smoke exposure, years & $35.1 \pm 12.5$ \\
\hline Wood smoke exposure, hour-years & $209.1 \pm 98.4$ \\
\hline Chronic cough ${ }^{b}$ & 29 (69.9) \\
\hline Expectoration $^{\mathrm{b}}$ & $24(55.8)$ \\
\hline Wheezing $^{\mathrm{b}}$ & $29(67.4)$ \\
\hline Dyspnea $^{b}$ & 35 (81.8) \\
\hline \multicolumn{2}{|l|}{ COPD severity ${ }^{b}$} \\
\hline Stage 1 (mild) & $9(21.4)$ \\
\hline Stage 11 (moderate) & $26(61.9)$ \\
\hline Stage 111 (severe) & $7(16.7)$ \\
\hline Stage IV (very severe) & $0(0.0)$ \\
\hline
\end{tabular}

${ }^{a}$ Values expressed as mean \pm SD, except where otherwise

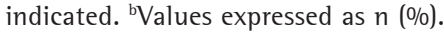

expectoration; wheezing; and dyspnea. Dyspnea was the most common complaint (Table 1), the Medical Research Council scale scores showing grade 1 or 2 dyspnea in 75\% of the cases and grade 3 or 4 in 25\%.

The females in the COPD group had mild to moderate airflow limitation (as determined by spirometry); none of the patients had severe obstructive lung disease (Table 1).

Regarding HRCT abnormalities, bronchiectasis, mosaic perfusion pattern, linear atelectasis (lobar atelectasis in one patient), and tree-in-bud pattern were significantly more common in the females in the COPD group than in those in the control group. None of the participants had panlobular emphysema. Lower lobe lesions predominated (Table 2 and Figure 1).

In the COPD group, we found statistically significant associations between bronchial wall thickening and cough $(\mathrm{p}=0.013 ; \mathrm{OR}=6.13$; 95\% Cl: 1.46-25.73) and between bronchial wall thickening and hour-years of wood smoke exposure $(p=0.018 ; O R=1.01 ; 95 \% \mathrm{Cl}: 1.01$ 1.02). We also found significant associations between centrilobular emphysema and duration of passive smoking $(\mathrm{p}=0.033 ; \mathrm{OR}=1.08 ; 95 \% \mathrm{Cl}$ :

Table 2 - HRCT findings in the COPD and control groups. $^{\mathrm{a}}$

\begin{tabular}{|c|c|c|c|}
\hline \multirow{2}{*}{ HRCT finding } & COPD & Control & \multirow{2}{*}{$\mathrm{p}$} \\
\hline & $(n=42)$ & $(n=31)$ & \\
\hline Normal & $0(0.0)$ & $1(3.2)$ & 0.417 \\
\hline Parenchymal bands & $33(78.6)$ & $7(22.6)$ & $<0.001^{*}$ \\
\hline $\begin{array}{l}\text { Bronchial wall } \\
\text { thickening }\end{array}$ & $28(66.7)$ & $0(0.0)$ & $<0.001$ \\
\hline Nodules & 26 (61.9) & $23(74.2)$ & 0.320 \\
\hline Bronchiectasis & $23(54.8)$ & $4(12.9)$ & $<0.001^{* *}$ \\
\hline $\begin{array}{l}\text { Traction } \\
\text { bronchiectasis }\end{array}$ & 7 (16.7) & $0(0.0)$ & 0.018 \\
\hline $\begin{array}{l}\text { Apical fibrosis/ } \\
\text { pleural scarring }\end{array}$ & $21(50.0)$ & $15(48.4)$ & 1.000 \\
\hline $\begin{array}{l}\text { Mosaic perfusion } \\
\text { pattern }\end{array}$ & $19(45.2)$ & $0(0.0)$ & $<0.001$ \\
\hline Atelectasis & $12(28.6)$ & $0(0.0)$ & 0.001 \\
\hline Tree-in-bud pattern & $9(21.4)$ & $1(3.2)$ & $0.037^{* * * *}$ \\
\hline $\begin{array}{l}\text { Mediastinal } \\
\text { lymphadenopathy }\end{array}$ & $6(14.3)$ & $2(6.5)$ & 0.454 \\
\hline $\begin{array}{l}\text { Centrilobular } \\
\text { emphysema }\end{array}$ & $5(11.9)$ & $1(3.2)$ & 0.232 \\
\hline Ground-glass opacity & $0(0.0)$ & $2(6.5)$ & 0.117 \\
\hline
\end{tabular}

avalues expressed as $\mathrm{n}(\%) .{ }^{*} \mathrm{OR}=12.57(95 \% \mathrm{Cl}$ : 4.1138.49). ${ }^{* *} \mathrm{OR}=8.17$ (95\% Cl: $\left.2.43-27.49\right) .{ }^{* * *} \mathrm{OR}=8.18$ (95\% Cl: 0.98-68.49). 


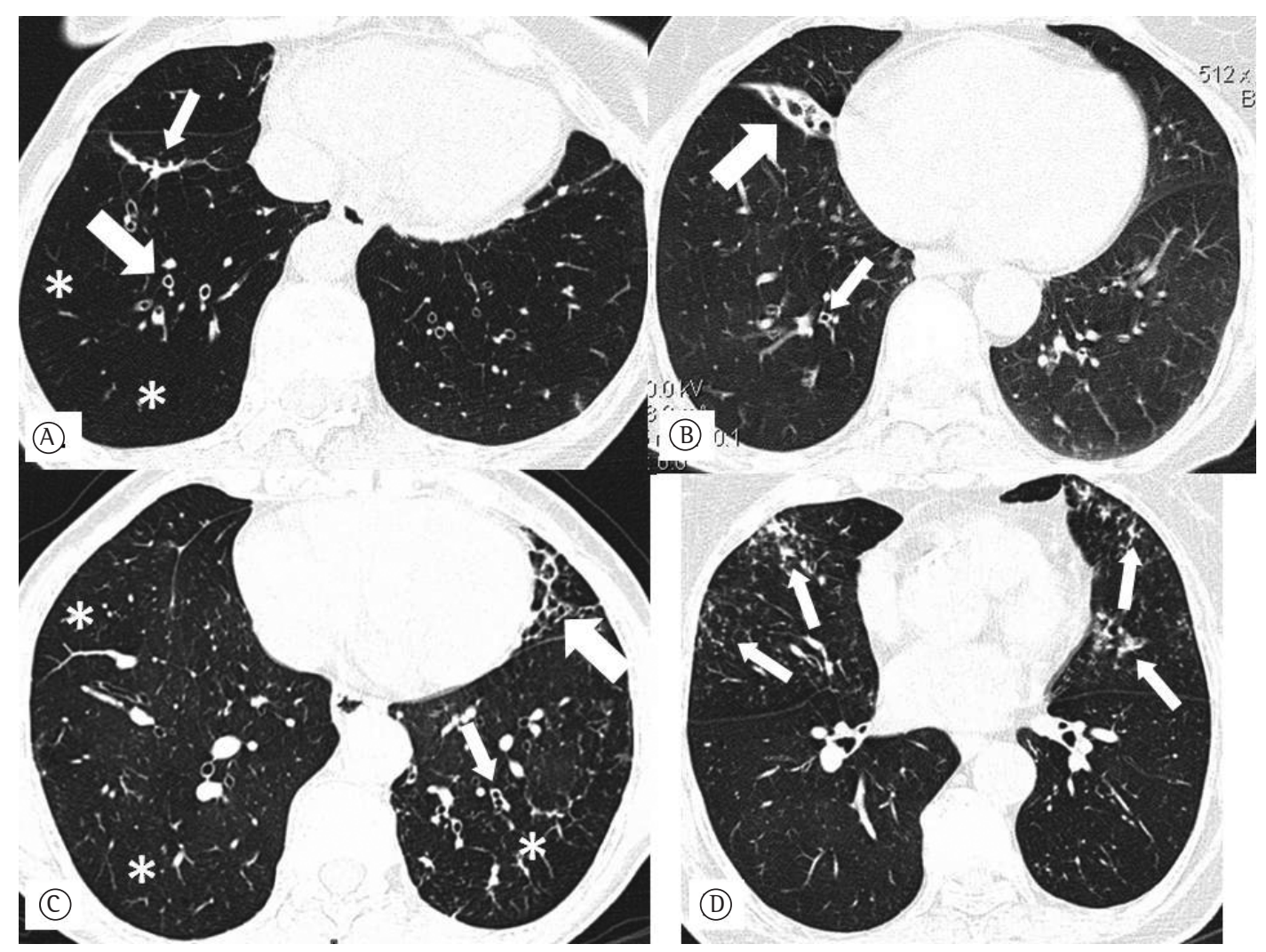

Figure 1 - Axial HRCT scans of the chest (lung window) at the level of the lower lung fields. In A, bronchiectasis and bronchial wall thickening (thick arrow), parenchymal bands (thin arrow), and mosaic perfusion pattern (asterisks) in a 66-year-old female patient. In B, middle lobe atelectasis (thick arrow) and bronchial wall thickening (thin arrow) in a 76-year-old female patient. In C, parenchymal bands (thick arrow), moderate bronchial wall thickening (thin arrow), and mosaic perfusion pattern (asterisks) in a 57-year-old female patient. In D, centrilobular micronodules with tree-in-bud pattern in an 81-year-old female patient.

1.01-1.16) and between mosaic perfusion pattern and lower $\mathrm{FEV}_{1}$ values $(\mathrm{p}=0.009 ; \mathrm{OR}=0.93$; 95\% Cl: 0.89-0.98).

In order to avoid bias due to possible structural lung changes occurring with age, we divided the participants into two new groups. Each group comprised 23 patients, the two groups being matched for age (Table 3).

After age matching, parenchymal bands, bronchial wall thickening, bronchiectasis, mosaic perfusion pattern, and laminar atelectasis were found to be significantly more common in the COPD group than in the control group. As can be seen in Table 4, those abnormalities occurred predominantly in the lower lung fields (in 76.6\%), having occurred in the middle lung fields in $15.6 \%$ and in the upper lung fields in $7.8 \%$.
The proportion of nodules on HRCT scans in the COPD group was equal to that of those on HRCT scans in the control group, most of the nodules being micronodules or calcified nodules.

\section{Discussion}

The present study examined pulmonary changes seen on HRCT scans in females with wood smoke-related COPD and showed that those changes were significantly more severe in those females than in those in the control group, who had no history of wood smoke exposure. The most common findings were parenchymal bands, bronchial wall thickening, bronchiectasis, mosaic attenuation/perfusion pattern, and linear atelectasis, the differences between the two groups being statistically significant. 
Table 3 - Demographic characteristics, data regarding wood smoke exposure, data regarding passive smoking, and pulmonary function test results in the COPD and control groups after adjustment for age. ${ }^{\mathrm{a}}$

\begin{tabular}{|c|c|c|c|}
\hline \multirow{2}{*}{ Variable } & COPD & Control & \multirow{2}{*}{$p$} \\
\hline & $(n=23)$ & $(n=23)$ & \\
\hline Age, years & $64.8 \pm 6.1$ & $61.6 \pm 6.66$ & 0.051 \\
\hline $\begin{array}{l}\text { Wood smoke } \\
\text { exposure, h/ } \\
\text { day }\end{array}$ & $6.5 \pm 2.1$ & - & - \\
\hline $\begin{array}{l}\text { Wood smoke } \\
\text { exposure, } \\
\text { years }\end{array}$ & $32.8 \pm 13.4$ & - & - \\
\hline $\begin{array}{l}\text { Wood smoke } \\
\text { exposure, } \\
\text { hour-years }\end{array}$ & $209.7 \pm 110.5$ & - & - \\
\hline $\begin{array}{l}\text { Passive } \\
\text { smoking }\end{array}$ & $26.5 \pm 19.9$ & $21.7 \pm 20.3$ & 0.424 \\
\hline $\begin{array}{l}\text { FVC, } \% \text { of } \\
\text { predicted }\end{array}$ & $91.8 \pm 13.1$ & $99.4 \pm 15.3$ & $<0.001$ \\
\hline $\begin{array}{l}\mathrm{FEV}_{1}, \% \text { of } \\
\text { predicted }\end{array}$ & $65.9 \pm 15.1$ & $104.5 \pm 12.6$ & $<0.001$ \\
\hline $\mathrm{FEV}_{1} / \mathrm{FVC}$ & $0.58 \pm 0.1$ & $0.80 \pm 0.1$ & $<0.001$ \\
\hline
\end{tabular}

${ }^{a}$ Values expressed as mean \pm SD.

Table 4 - HRCT findings in the COPD and control groups after adjustment for age. ${ }^{\text {a }}$

\begin{tabular}{lccc}
\hline \multirow{2}{*}{ HRCT finding } & COPD & Control & \multirow{2}{*}{$\mathrm{p}$} \\
\cline { 2 - 3 } & $(\mathrm{n}=23)$ & $(\mathrm{n}=23)$ & \\
\hline Parenchymal bands & $20(86.9)$ & $4(17.4)$ & $<0.001^{*}$ \\
$\begin{array}{l}\text { Bronchial wall } \\
\text { thickening }\end{array}$ & $14(60.9)$ & $0(0.0)$ & $<0.001$ \\
Bronchiectasis & $10(43.5)$ & $4(17.4)$ & $0.047^{* *}$ \\
Mosaic perfusion & $7(30.4)$ & $0(0.0)$ & 0.009 \\
pattern & & & \\
Atelectasis & $7(30.4)$ & $0(0.0)$ & 0.009 \\
Tree-in-bud pattern & $5(21.7)$ & $1(4.3)$ & 0.187 \\
\hline
\end{tabular}

${ }^{a}$ Values expressed as $\mathrm{n}(\%) .{ }^{*} \mathrm{OR}=22.56(95 \% \mathrm{Cl}$ : 4.91103.66). ${ }^{* *} \mathrm{OR}=5.13(95 \% \mathrm{Cl}: 1.18-22.24)$.

It is known that wood combustion produces various substances that are harmful to the lungs, including carbon monoxide, nitrogen oxide, particulate matter, polycyclic aromatic hydrocarbons, and formaldehyde, and that are also present in cigarette smoke; wood smoke exposure can therefore cause changes that are similar to those caused by smoking. ${ }^{(26)}$

In the present study, the most common findings were parenchymal bands, which are changes indicative of parenchymal fibrosis. ${ }^{(23)}$ These changes have been associated with exposure to biomass smoke and wood smoke in pathological and CT studies, which have suggested that such changes correspond to an initial interstitial involvement. ${ }^{(5,6)}$

Although we found no areas of significant interstitial involvement in the present study, three studies have described such areas. ${ }^{(5-7)}$ Parenchymal bands and ground-glass opacities were also found in those studies, having been reported to be quite common in one of the studies. ${ }^{(6)}$ In the present study, we found no ground-glass opacities, which are associated with interstitial thickening and alveolar collapse. ${ }^{(23)}$ However, the females investigated in the abovementioned studies ${ }^{(5-7)}$ had been exposed to mixed biomass, which includes dung and wood. Dung combustion generates more pollutants than does wood combustion, ranking lower on the energy scale for being less efficient and more polluting. ${ }^{(27)}$ The differences among the results obtained can be explained by the different types of biomass used and the different purposes for which it is used.

Bronchial wall thickening was the second most common finding in the present study, having remained so after adjustment for age. This shows that bronchial wall thickening was unrelated to aging.

Bronchiectasis has been found in all studies examining exposure to biomass smoke ${ }^{(5-7)}$ and was the fourth most prevalent type of lesion in the present study, having been found in $54.8 \%$ of the females exposed to wood smoke and in $12.5 \%$ of those in the control group. Even after adjustment for age, bronchiectasis was significantly more common in the group of females exposed to wood smoke. This shows that bronchiectasis is not associated with lung aging. Unlike bronchiectasis resulting from a specific disease, which tends to accumulate in a localized area of the lung, the bronchiectasis found in the present study was homogeneously distributed in the lungs and was predominantly located in the lower lobes.

Mosaic perfusion pattern, which has been described as a CT manifestation of obstructive lung disease, ${ }^{(23)}$ was found in nearly half of the COPD patients in the present study and was found to be independent of age.

In the present study, atelectasis was found only in the COPD group, having persisted after age matching. The presence of bronchial anthracosis, which causes atelectasis, has been reported in females exposed to biomass smoke. ${ }^{(28)}$ 
A study of women exposed to wood smoke found "pseudoemphysema" and hyperinflation on CT scans, and it was suggested that those changes were due to pronounced bronchial involvement, given that there were no changes in lung elastic recoil, which are typically seen in cases of emphysema ${ }^{(9)}$ Emphysema is an unusual finding in individuals exposed to biomass smoke and, when present, is usually less pronounced than is that observed in individuals with smokingrelated COPD. ${ }^{(9)}$

In the present study, we found centrilobular emphysema, which was positively associated with duration of passive smoking. Although it was weak, this association suggests that passive smoking contributes to the development of emphysema. Another relevant finding of the present study was the association between bronchial wall thickening and chronic cough. We found a weak but positive association between bronchial wall thickening and duration of exposure to biomass smoke. This finding had not been reported in the literature, an association between obstructive functional impairment and duration of exposure to biomass smoke having previously been reported. ${ }^{(6)}$

We found an association between mosaic perfusion pattern, which is suggestive of obstructive lung disease, ${ }^{(23)}$ and lower $\mathrm{FEV}_{1}$ and $\mathrm{FEV}_{1} / \mathrm{FVC}$ values.

Age-related CT abnormalities, principally bronchial abnormalities, have been reported in individuals over 65 years of age, regardless of their smoking history. ${ }^{(26)}$ However, even after adjustment for age, the difference between the COPD and control groups regarding the frequency of changes persisted, the exception being tree-in-bud pattern. This demonstrated that the changes previously seen in the COPD group were related to wood smoke exposure rather than to aging.

One study established a relationship between various COPD phenotypes and CT findings. ${ }^{(29)}$ One of those phenotypes, reported in nonsmokers, included minimal emphysema, bronchial wall thickening, mild hyperinflation, and high body mass index values. The abovementioned phenotype partly coincides with the phenotype found in the present study.

Most of the patients in the present study had mild to moderate COPD. This can partially explain why those patients had milder HRCT abnormalities, which are also seen in patients with smoking-related COPD. ${ }^{(4)}$

The proportion of apical fibrosis/pleural scarring seen in the COPD group was the same as that seen in the control group, as was the proportion of tree-in-bud pattern. Those changes might be due to pulmonary tuberculosis or infectious bronchitis. However, none of the females investigated in the present study reported a history of tuberculosis, and none had a clinical profile suggestive of active tuberculosis or bronchial infection.

The present study has limitations. Some of the data were collected by means of a questionnaire, and questionnaires depend on the ability of respondents to recollect specific information. This problem is mitigated by the fact that the questionnaire used in the present study had previously been used in Brazil and by the fact that the interviewers were extensively trained in order to obtain information by objectively referring to specific aspects of the lives of the participants. Another limitation of the present study was the lack of an objective measurement of the degree of pollution at the place of residence of the females who used wood stoves. Finally, we did not take HRCT scans during an expiratory maneuver. Such scans facilitate the visualization of small airway abnormalities. However, blinded individual assessment, followed by consensus among three experienced radiologists, probably minimized this limitation.

Relevant aspects of the present study were the fact that all patients and controls underwent spirometry; we collected data regarding exposure to wood smoke only, data regarding other types of exposure having been excluded; and we established a minimum duration of exposure to wood smoke as a criterion for inclusion in the present study. Another relevant aspect of the present study is that we found no similar studies in the literature. In our study, we evaluated a control group of nonsmoking females with no history of exposure to biomass smoke, having performed adjustment for age and having used HRCT scans in order to describe the effects of exposure to wood smoke alone on the lungs of nonsmoking females with COPD.

We can conclude that wood smoke inhalation causes lung legions predominantly in the airways. These lesions can be detected by HRCT, even in patients with mild to moderate COPD. This finding is important because it shows that individuals exposed to wood smoke can present with pulmonary 
changes despite being nearly asymptomatic and therefore should be treated early.

\section{References}

1. Desai MA, Mehta S, Smith KR. Indoor Smoke from Solid Fuels: Assessing the Environmental Burden of Disease at National and Local Levels. Geneva: Protection of the Human Environment, World Health Organization; 2004.

2. Torres-Duque C, Maldonado D, Pérez-Padilla R, Ezzati M, Viegi G; Forum of International Respiratory Studies (FIRS) Task Force on Health Effects of Biomass Exposure. Biomass fuels and respiratory diseases: a review of the evidence. Proc Am Thorac Soc. 2008;5(5):577-90.

3. Salvi S, Barnes PJ. ls exposure to biomass smoke the biggest risk factor for COPD globally? Chest. 2010;138(1):3-6.

4. Gupta PP, Yadav R, Verma M, Agarwal D, Kumar M. Correlation between high-resolution computed tomography features and patients' characteristics in chronic obstructive pulmonary disease. Ann Thorac Med. 2008;3(3):87-93.

5. Arslan M, Akkurt 1, Egilmez H, Atalar M, Salk 1. Biomass exposure and the high resolution computed tomographic and spirometric findings. Eur J Radiol. 2004;52(2):192-9.

6. Kara M, Bulut S, Tas F, Akkurt I, Seyfikli Z. Evaluation of pulmonary changes due to biomass fuels using high-resolution computed tomography. Eur Radiol. 200;13(10):2372-7.

7. Ozbay B, Uzun K, Arslan H, Zehir l. Functional and radiological impairment in women highly exposed to indoor biomass fuels. Respirology. 2001;6(3):255-8.

8. Amoli K. Bronchopulmonary disease in Iranian housewives chronically exposed to indoor smoke. Eur Respir J. 1998;11(3):659-63.

9. González M, Maldonado D, Pérez J, Varón H. Pseudophysiologic emphysema in women with wood smoke COPD in Bogota (2600 m) [Article in Spanish] Arch Bronconeumol. 2004;40:31.

10. Gupta A, Shah A. Bronchial anthracofibrosis: an emerging pulmonary disease due to biomass fuel exposure. Int $\mathrm{J}$ Tuberc lung Dis. 2011;15(5):602-12.

11. Kim HY, Im JG, Goo JM, Kim JY, Han SK, Lee JK, Song JW. Bronchial anthracofibrosis (inflammatory bronchial stenosis with anthracotic pigmentation): CT findings. AJR Am J Roentgenol. 2000;174(2):523-7.

12. Torun T, Gungor G, Ozmen I, Maden E, Bolukbasi Y, Tahaoglu K. Bronchial anthracostenosis in patients exposed to biomass smoke. Turkish Respir J. 2007;8(2):48-51.

13. Kala J, Sahay S, Shah A. Bronchial anthracofibrosis and tuberculosis presenting as a middle lobe syndrome. Prim Care Respir J. 2008;17(1):51-5.

14. Kim YJ, Jung CY, Shin HW, Lee BK. Biomass smoke induced bronchial anthracofibrosis: presenting features and clinical course. Respir Med. 2009;103(5):757-65.

15. Pellegrino R, Viegi G, Brusasco V, Crapo RO, Burgos F, Casaburi R, et al. Interpretative strategies for lung function tests. Eur Respir J. 2005;26(5):948-68.

16. Menezes AM, Jardim JR, Pérez-Padilla R, Camelier A, Rosa F, Nascimento O, et al. Prevalence of chronic obstructive pulmonary disease and associated factors: the PlATiNO Study in São Paulo, Brazil. Cad Saude Publica. 2005;21(5):1565-73.

17. Bestall JC, Paul EA, Garrod R, Garnham R, Jones PW, Wedzicha JA. Usefulness of the Medical Research Council (MRC) dyspnoea scale as a measure of disability in patients with chronic obstructive pulmonary disease. Thorax. 1999;54(7):581-6.

18. Ramírez-Venegas A, Sansores RH, Pérez-Padilla R, Regalado J, Velázquez A, Sánchez C, et al. Survival of patients with chronic obstructive pulmonary disease due to biomass smoke and tobacco. Am J Respir Crit Care Med. 2006;173(4):393-7.

19. Vollmer WM, Gíslason T, Burney P, Enright PL, Gulsvik A, Kocabas A, et al. Comparison of spirometry criteria for the diagnosis of COPD: results from the BOLD study. Eur Respir J. 2009;34(3):588-97.

20. Global Initiative for Chronic Obstructive Disease - GOLD [homepage on the Internet]. Bethesda: Global Initiative for Chronic Obstructive Disease. [cited 2011 Mar 10]. Global Strategy for the Diagnosis, Management, and Prevention of COPD 2010. [Adobe Acrobat document, 117p.]. Available from: http://www.goldcopd.org/uploads/ users/files/GOLDReport_April112011.pdf

21. Miller MR, Hankinson J, Brusasco V, Burgos F, Casaburi $\mathrm{R}$, Coates A, et al. Standardisation of spirometry. Eur Respir J. 2005;26(2):319-38.

22. Pereira CA, Sato T, Rodrigues SC. New reference values for forced spirometry in white adults in Brazil. J Bras Pneumol. 2007;33(4):397-406.

23. Silva $\mathrm{Cl}$, Marchiori E, Souza Júnior AS, Müller NL; Comissão de lmagem da Sociedade Brasileira de Pneumologia e Tisiologia. Illustrated Brazilian consensus of terms and fundamental patterns in chest CT scans. J Bras Pneumol. 2010;36(1):99-123.

24. Copley SJ, Wells AU, Hawtin KE, Gibson DJ, Hodson JM, Jacques AE, et al. Lung morphology in the elderly: comparative CT study of subjects over 75 years old versus those under 55 years old. Radiology. 2009;251(2):566-73.

25. Roberts HR, Wells AU, Milne DG, Rubens MB, Kolbe J, Cole PJ, et al. Airflow obstruction in bronchiectasis: correlation between computed tomography features and pulmonary function tests. Thorax. 2000;55(3):198-204.

26. Vikgren J, Boijsen M, Andelid K, Ekberg-Jansson A, Larsson S, Bake B, et al. High-resolution computed tomography in healthy smokers and never-smokers: a 6-year follow-up study of men born in 1933. Acta Radiol. 2004;45(1):44-52. Erratum in: Acta Radiol. 2004;45(3):following 663.

27. Junemann A, Legarreta CG. Chronic obstructive pulmonary disease produced by biomass fuels. Clin Pulm Med. 2008;15(6):305-12.

28. González M, Páez S, Jaramillo C, Barrero M, Maldonado D. Enfermedad pulmonar obstructiva crónica (EPOC) por humo de leña en mujeres. Acta Med Colomb. 2004;29(1):17-25.

29. Kitaguchi Y, Fujimoto K, Kubo K, Honda T. Characteristics of COPD phenotypes classified according to the findings of HRCT. Respir Med. 2006;100(10):1742-52. 


\section{About the authors}

Maria Auxiliadora Carmo Moreira

Associate Professor. Federal University of Goiás School of Medicine, Goiânia, Brazil.

\section{Maria Alves Barbosa}

Full Professor. Federal University of Goiás School of Nursing, Goiânia, Brazil.

\section{Maria Conceição de Castro Antonelli Monteiro de Queiroz}

Attending Physician. Department of Pulmonology, Federal University of Goiás School of Medicine Hospital das Clínicas, Goiânia, Brazil.

Kim Ir Sen Santos Teixeira

Adjunct Professor. Department of Diagnostic lmaging and Pathology, Federal University of Goiás School of Medicine, Goiânia, Brazil.

Pedro Paulo Teixeira e Silva Torres

Substitute Professor. Department of Diagnostic Imaging and Pathology, Federal University of Goiás School of Medicine, Goiânia, Brazil.

\section{Pedro José de Santana Júnior}

Volunteer Radiologist. Department of Diagnostic Imaging and Pathology, Federal University of Goiás School of Medicine, Goiânia, Brazil.

\section{Marcelo Eustáquio Montadon Júnior}

Radiologist. Clínica Multimagem Diagnósticos, Goiânia, Brazil

\section{José Roberto Jardim}

Tenured Professor. Federal University of São Paulo Paulista School of Medicine, São Paulo, Brazil. 